\title{
Dissemination and Refutation of Rumors During the COVID-19 Outbreak in China: Infodemiology Study
}

Bin Chen ${ }^{1,2^{*}}$, MD; Xinyi Chen ${ }^{3 *}, \mathrm{MD}$; Jin Pan ${ }^{4 *}, \mathrm{MD}$; Kui Liu ${ }^{1 *}, \mathrm{MD}$; Bo Xie ${ }^{5}$, PhD; Wei Wang ${ }^{1}$, MD; Ying Peng ${ }^{1}$, MD; Fei Wang ${ }^{1}$, MD; $\mathrm{Na} \mathrm{Li}^{6}$, MD; Jianmin Jiang ${ }^{1,7}$, MD, PhD

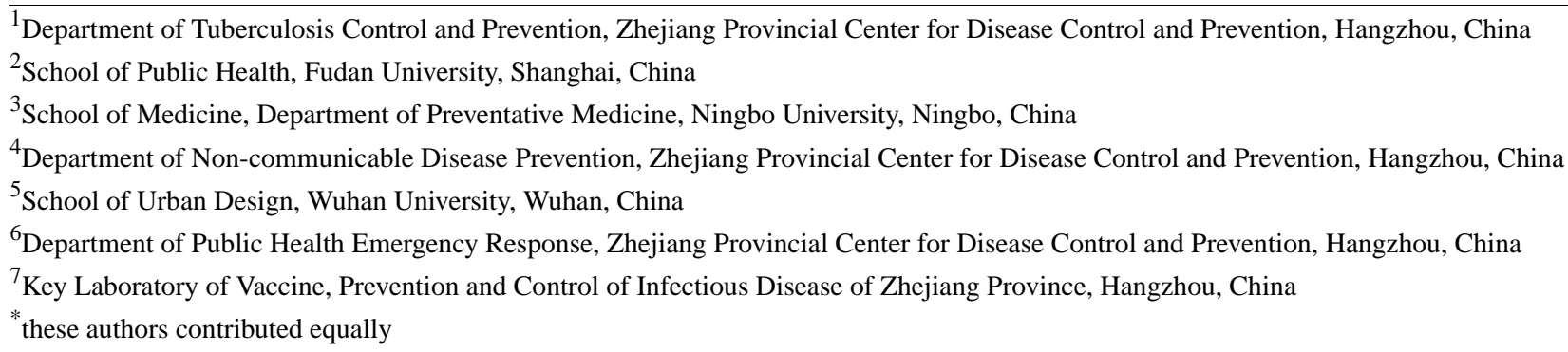

Corresponding Author:

Jianmin Jiang, MD, PhD

Department of Tuberculosis Control and Prevention

Zhejiang Provincial Center for Disease Control and Prevention

Binsheng Road 3399

Binjiang District

Hangzhou, 310051

China

Phone: 8657187115009

Fax: 8657187115009

Email: jmjiang@cdc.zj.cn

\section{Abstract}

Background: During the outbreak of COVID-19, numerous rumors emerged on the internet in China and caused confusion among the public. However, the characteristics of these rumors in different phases of the epidemic have not been studied in depth, and the official responses to the rumors have not been systematically evaluated.

Objective: The aims of this study were to evaluate the rumor epidemic and official responses during the COVID-19 outbreak in China and to provide a scientific basis for effective information communication in future public health crises.

Methods: Data on internet rumors related to COVID-19 were collected via the Sina Weibo Official Account to Refute Rumors between January 20 and April 8, 2020, extracted, and analyzed. The data were divided into five periods according to the key events and disease epidemic. Different classifications of rumors were described and compared over the five periods. The trends of the epidemic and the focus of the public at different stages were plotted, and correlation analysis between the number of rumors and the number of COVID-19 cases was performed. The geographic distributions of the sources and refuters of the rumors were graphed, and analyses of the most frequently appearing words in the rumors were applied to reveal hotspots of the rumors.

Results: A total of 1943 rumors were retrieved. The median of the response interval between publication and debunking of the rumors was 1 day (IQR 1-2). Rumors in text format accounted for the majority of the 1943 rumors $(\mathrm{n}=1241,63.9 \%)$; chat tools, particularly WeChat $(\mathrm{n}=1386,71.3 \%)$, were the most common platform for initial publishing of the rumors $(\mathrm{n}=1412,72.7 \%)$. In addition to text rumors, Weibo and web pages were more likely to be platforms for rumors released in multimedia formats or in a combination of formats, respectively. Local agencies played a large role in dispelling rumors among social media platforms $(1537 / 1943,79.1 \%)$. There were significant differences in the formats and origins of rumors over the five periods $(P<.001)$. Hubei Province accounted for most of the country's confirmed rumors. Beijing and Wuhan City were the main centers for debunking of disinformation. The words most frequently included in the core messages of the rumors varied by period, indicating shifting in the public's concern. 
Conclusions: Chat tools, particularly WeChat, became the major sources of rumors during the COVID-19 outbreak in China, indicating a requirement to establish rumor monitoring and refuting mechanisms on these platforms. Moreover, targeted policy adjustments and timely release of official information are needed in different phases of the outbreak.

(J Med Internet Res 2021;23(2):e22427) doi: 10.2196/22427

\section{KEYWORDS}

rumor; Internet; COVID-19; epidemic; misinformation; infodemiology; infodemic; social media; communication; public health

\section{Introduction}

In December 2019, an outbreak of COVID-19, caused by infection with SARS-CoV-2, emerged in Wuhan, Hubei Province, China, and subsequently became a global pandemic [1-3]. As of July 1, 2020, more than 10.3 million cases had been confirmed in most countries and territories worldwide, with more than 508,000 fatalities [4], seriously threatening the lives and health of the public and jeopardizing the stable economic development and social safety of nations.

Internet public opinion crises characterized by frequent rumors often accompany public health emergencies, especially when information from official authorities is delayed or lacking [5]. Since the advent of Web 2.0 technology, internet social media platforms such as WeChat (similar to WhatsApp) and Weibo (similar to Twitter) have gradually replaced traditional media as the main platforms for the public to express their opinion and participate in social affairs in China. Due to the easy accessibility and convenience of social media, information spreads more rapidly and widely through these platforms than through their conventional counterparts [6]; moreover, the resulting large availability of user-provided content fosters massive recruitment of people around common interests, worldviews, and narratives, thus affecting the evolution of public opinion [7] and further enabling rumors to flourish. In 2013, the World Economic Forum described web-based rumors as "digital wildfire" and highlighted the risks they pose to modern society [8]. The rumor that drinking spirit can prevent infection with SARS-CoV-2 is a typical example of a rumor that spread during the outbreak of COVID-19 in China. From the beginning of the outbreak, social media users started to query about methods of preventing and treating COVID-19, and they rushed to the internet to seek information. Due to strong concerns about their own lives and the lack of awareness of the disease, many microbloggers released messages that misrepresented the causal relationship between COVID-19 and drinking spirit, and their posts became very prevalent [9]. This false message was widely discussed on the internet at the time and caused great confusion and panic. As a result, the government provided an official clarification of the rumor, and various localities promptly refuted the rumor and addressed it through the intervention of public security departments, which prevented the rumor from spreading further.

According to previous research, public opinion events are often caused by the interaction of events, the public, social media platforms, and structural factors of the government [10,11]. Public health emergencies, especially outbreaks of new infectious diseases, are often accompanied by uncertainty about the cause of the emergency. However, the resulting information on the morbidity and mortality of the diseases becomes the focus of public concern from the moment it emerges. Individuals' perceptions of the threat of diseases tends to be reinforced by their exposure to case data and also by public and private information that is disseminated widely on social media [12]. Simultaneously, the unknown causes of public health emergencies stimulate increased information-seeking behavior in people who are aiming to reduce their uncertainties about the emergent situation [13]. However, in the absence of information, people experience a wide range of emotions in the face of unexpected situations, and the anxiety or fear thus generated can exacerbate the occurrence and dissemination of rumors [14]. The role of government intervention in the development trend of rumors remains uncertain. However, the subject, duration, methods, and level of government intervention have certain influences on the virality of rumors [10]. In addition to the professional measures of epidemic prevention and control, keeping the information accurate and transparent and preventing the spread of rumors are critical parts of the crisis response, reflecting the significance of the establishment of government monitoring-feedback-intervention mechanisms in public health emergencies [15].

Compared with the severe acute respiratory syndrome (SARS) outbreak 17 years ago, the COVID-19 outbreak has sparked more rumormongering. Rumors such as "dual yellow oral liquid inhibited novel coronavirus," "number of confirmed cases of COVID-19 and deaths in a county," and "some places have been blockaded or the supermarkets have been closed down" sparked panic among the public, causing people to rush to buy supplies and posing a serious challenge to the governance of internet public opinion in the context of the epidemic. As the challenges grew in the face of the public crisis, the phenomenon of the "infodemic," an overabundance of accurate or inaccurate information occurring during an epidemic, has escalated to a level that requires a coordinated response. Thus, the emerging research area of "infodemiology," which can be defined as the science of using epidemiologic methods and terminology to study the distribution and determinants of information in an electronic medium, specifically the internet, with the ultimate aim to inform public health and public policy, has been developed [16] and was effectively used to predict the influenza outbreak in 2006 [17]. Infodemiology data are derived from unstructured, textual, openly accessible information produced and consumed by the public on the internet to demonstrate and explore the opinions, focus, behavior, attitudes, and knowledge of the public [16]. The research field of infodemiology has gradually gained wider use, and it caught the attention of the World Health Organization in the wake of the COVID-19 outbreak [18], encouraging the undertaking of more relevant 
studies and effective practices to understand more about internet information.

Thus, in this study, we analyzed rumors collected from rumor-refuting platforms, using the methods of infodemiology from the supply side, to understand the epidemic of rumors and official responses in different periods according to typical events and the disease epidemic. The results of this study could provide evidence-based recommendations for information communication and rumor prevention during subsequent public health emergencies.

\section{Methods}

\section{Data Sources}

Between January 20, 2020 (the day the national authority first published the official announcement of human-to-human transmission of COVID-19), and April 8, 2020 (the day the lockdown was lifted in Wuhan), daily reports of identified and confirmed rumors and counterrumors of the COVID-19 outbreak were collected through the Sina Weibo Official Account to Refute Rumors (hereinafter referred to as "the Rumors on Weibo account") [19]. Launched in 2010, this account has been dedicated to rumor-busting and has now become one of the largest accounts in China, with more than 2.16 million registered users and subscribers; it contains a massive amount of information collected from most official platforms, such as the

Figure 1. Flowchart of the selection of rumor posts.
Chinese National Platform to Refute Rumors, WeChat Disinformation Platform, internet media, and web pages of government authorities, to refute rumors. Each post in the Rumors on Weibo account contains a rumor message and related rumor-refuting information.

During the first week of the study period (January 20-27), a small sample of 311 rumor messages was collected via the Rumors on Weibo account, and word frequency analysis was performed on these messages. After a panel discussion, 新型 (novel), 冠状 (corona-), 病毒 (virus), 新冠 (the Chinese abbreviation for COVID-19), and 肺炎 (pneumonia) were selected as the 5 keywords according to their frequency in the rumor posts. A total of 6839 disinformation messages were retrieved on the Rumors on Weibo account based on these keywords during the whole study period, of which 5303 were duplicated; eventually, 1536 rumor messages related to the epidemic were included. Meanwhile, other rumor posts not containing the above keywords were reviewed manually in the Rumors on Weibo account each week. A total of 407 relevant rumor messages, not containing the above 5 keywords, were also retrieved and added to the database (Figure 1). The initial posting time, title, posting platform, geographic location, format of each rumor, rumor-refuting time, and number of retweets of each rumor post were extracted and entered into the database. All the information obtained on the web was in simplified Chinese language and released publicly by the websites; however, no personal identification information was collected.

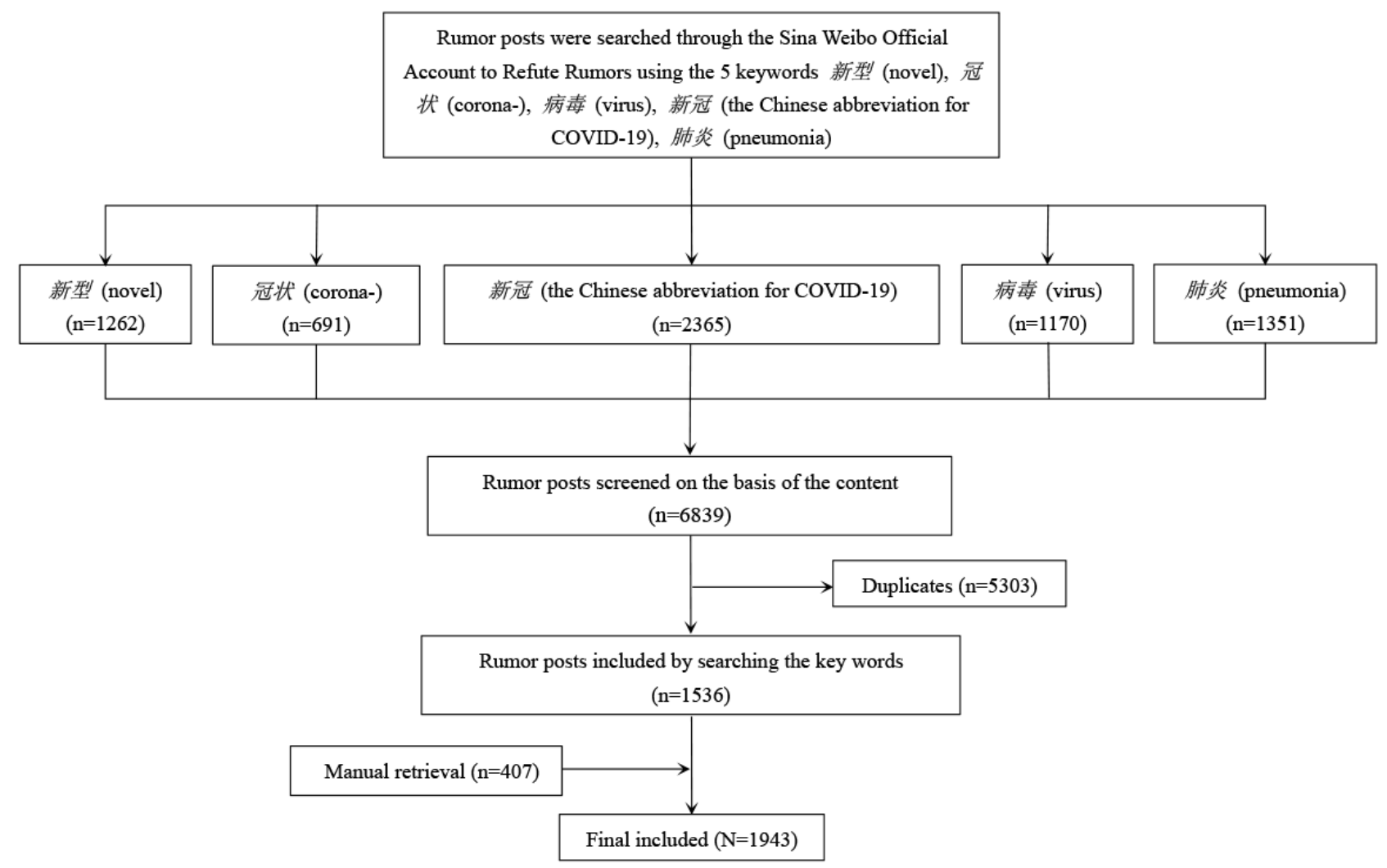




\section{Classification of the Five Time Periods}

To better reflect the dynamics of the spread of rumors, five time periods were classified based on key events of the disease epidemic that could affect the dissemination of rumors on the internet (Figure 2). The time period between January 20, 2020 (the date of the first official announcement of human-to-human transmission and infection of SARS-CoV-2), and January 24, 2020, was taken as the first period in this study [20]. During this period, the National Health Commission issued a bulletin that COVID-19 had been incorporated into the management of the Prevention and Control of Infectious Diseases Act [21], and many local governments had launched first-level responses in the face of the outbreak. On January 23, the Wuhan government blocked all outbound transportation from the city with traffic suspension and home quarantine within the city [22]. The second period was January 24 to February 4; during this time, the number of new confirmed cases in China was gradually rising, and it reached its highest daily increase on February 4 [23]. From February 5 to February 12 (the third period), there was a steady decrease in the daily report of new confirmed cases. However, the secondary peak of the case numbers was reached on February 12 due to reports of clinically diagnosed cases [24]. From then until February 26 (the fourth period), the domestic epidemic gradually declined; meanwhile, foreign cases surpassed the domestic numbers for the first time by February 26. The fifth period was February 27 to April 8, when the domestic epidemic situation continued to decline and the epidemic situation in Wuhan gradually improved. On April 8, Wuhan government announced that the lockdown of the city had ended [25].

Figure 2. Daily numbers of rumors detected and refuted, the epidemic curve, and key events across five periods of the COVID-19 outbreak in China. The inset shows a magnified view of the number of COVID-19 cases over the last two periods.

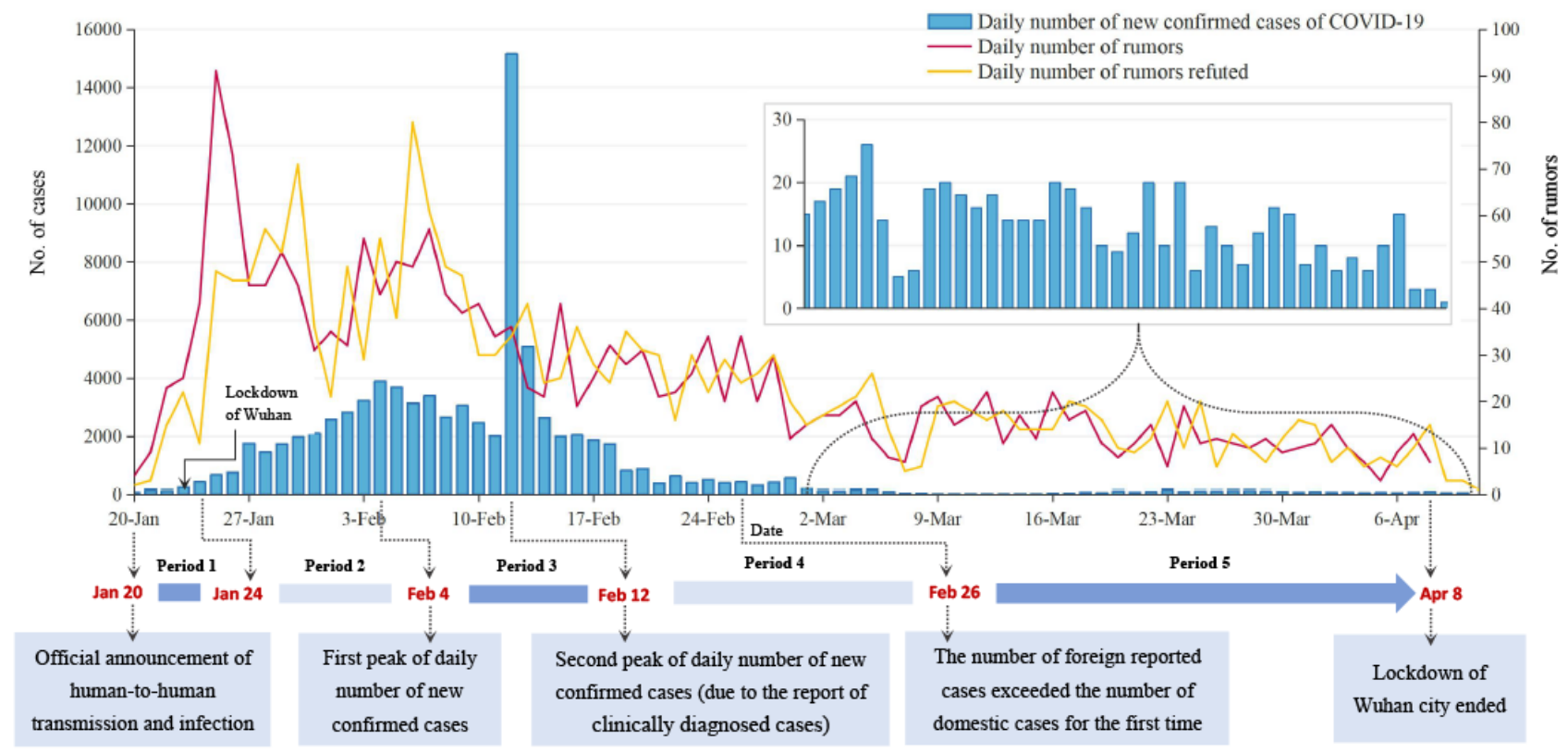

\section{Classification and Definition of Information Sources for Rumors}

The rumor information sources were divided into the following categories according to their original publishing platforms: chat tools, Weibo, web pages, and others. Chat tools included WeChat and Tencent QQ. Both of these tools are major social media platforms in China that enable people to chat, communicate, and post events or opinions that others can comment on. If a rumor was first published on Weibo, the Twitter-like platform, which enables users to repost or comment, its information source was classified as Weibo. Web pages represented a number of rumors published in the form of web links. "Others" indicated some platforms that could not be classified in any of the above categories, including several mobile apps, such as TikTok, and platforms on which the source of the rumor could not be traced.

\section{Classification and Definition of Rumor Refuters}

According to the level of representativeness and influence, the rumor refuters were divided into three main categories: national, local, and other. "National" indicated that the official accounts of the rumor refuters were set up by national departments or institutions for publishing official state news or policies. Accounts established by relevant local agencies for publishing local news were classified as local, and other accounts that could not be classified in either of the above categories were classified as others; these users mainly included certified individual accounts, foreign accounts, and certified accounts of nonstate, nonlocal business firms. Meanwhile, based on the essential attributes and affiliations of different rumor refuters, all of them were further classified as government authorities, news media, and organizations, companies, or individuals. All data were classified based on the classification criteria outlined by two researchers. A third reviewer discussed the different classifications with the two reviewers and finalized the categorization. Some sample accounts are listed in Table 1. 
Table 1. The criteria of the categories for the rumor refuters and the sample accounts.

\begin{tabular}{|c|c|c|}
\hline Category of rumor refuter & Definition & Sample accounts \\
\hline \multicolumn{3}{|l|}{ Level of representativeness and influence } \\
\hline National & $\begin{array}{l}\text { Official accounts set up by national departments or institu- } \\
\text { tions for publishing official state news or policy }\end{array}$ & $\begin{array}{ll}\text { - } & \text { CCTV News } \\
\text { - Chinese National Platform to Re- } & \text { fute Rumors } \\
\text { - } & \text { China Science Communication }\end{array}$ \\
\hline Local & $\begin{array}{l}\text { Accounts established by relevant local agencies for publish- } \\
\text { ing local news }\end{array}$ & $\begin{array}{ll}\text { - } & \text { Wuhan Release } \\
\text { - } & \text { Nanjing Release } \\
\text { - } & \text { Shanghai Customs }\end{array}$ \\
\hline Others & $\begin{array}{l}\text { Accounts that could not be classified into the categories } \\
\text { above }\end{array}$ & $\begin{array}{ll}\text { - } & \text { Alipay } \\
\text { - } & \text { Doctor Guan }\end{array}$ \\
\hline \multicolumn{3}{|l|}{ Essential attributes and affiliations } \\
\hline Government authorities & $\begin{array}{l}\text { Official accounts established by government departments } \\
\text { for the publication of government-related information }\end{array}$ & $\begin{array}{ll}\text { - } & \text { Wuhan Release } \\
\text { - } & \text { Fuyang Health Committee } \\
\text { - Jiangxi Public Security Depart- } \\
\text { ment }\end{array}$ \\
\hline News media & Official accounts of news media websites & $\begin{array}{ll}\text { - } & \text { CCTV News } \\
\text { - } & \text { Wuhan Daily News } \\
\text { - } & \text { People's Daily }\end{array}$ \\
\hline Organizations/companies/individuals & $\begin{array}{l}\text { Accounts of some nongovernmental organizations and } \\
\text { corporate and individual accounts. }\end{array}$ & $\begin{array}{ll}\text { - } & \text { Beijing Public Transportation } \\
\text { group } \\
\text { - } \quad \text { Ding Talk } \\
\text { - } \quad \text { Alipay }\end{array}$ \\
\hline
\end{tabular}

\section{Analysis of Most Frequently Appearing Words in Rumors}

Rumor word frequency analysis was carried out using Python version 2.7. The jieba package was employed as a text analysis tool for processing the core message of each rumor. The core message of every rumor in our study was summarized by the Rumors on Weibo account, which captured the main point of the content of the entire rumor well. Additionally, the rumors presented in the forms of images, videos, and audio were also translated by extracting the core message of that rumor through the official rumor-refuting account. Accordingly, all the rumor information in this study consisted of brief textual sentences. First, the spaces and newlines were removed from the text; then, all the punctuation marks in the text were replaced with spaces. The processed text was partitioned using the jieba package, and stop words such as "have," "is," "will," "can," and "have been" were removed from the text according to a predefined list of deactivated words. After the data set was created, a corpus of rumors was formed.

Based on the collection and classification of the rumor corpus obtained by preprocessing, the lists of words were filtered and merged according to an expert's opinion, and the data set of rumor features was finally obtained. The weight of every term was calculated using the term frequency-inverse document frequency (TF-IDF) method using the equation below:

$$
\mathrm{TF}-\operatorname{IDF}\left(f_{k} d_{k}\right)=\left(f_{k} d_{k}\right) \log \frac{T}{T\left(f_{k}\right)+1}
$$

The formula is divided into two parts; $\left(f_{k} d_{k}\right)$ to the left of the equal sign represents the word frequency, which is the number of times a word appears in the text. The higher the number of occurrences of a word, the greater the role it plays in the text. In contrast, $\left(f_{k} d_{k}\right)$ to the right of the equals sign is the logarithm value of the inverse document frequency. $T$ represents the number of texts in the corpus, and $T\left(f_{k}\right)$ indicates the number of texts containing specific terms in the corpus.

The word cloud of rumors about COVID-19 during the whole study period was visualized using the wordcloud package; moreover, the summary of the top 20 high-frequency keywords of the rumors based on the term frequency-inverse document frequency (TF-IDF) values over each period was used to analyze the changes in the same keyword at different stages, which may further reflect the shifts in the public's focus.

\section{Statistical Analysis}

Excel (Microsoft Corporation) was used to record and sort information about the rumors. The epidemic curve, daily number of rumors released and clarified, new confirmed cases of COVID-19, and key events across the five periods were plotted to comprehensively analyze the relationship between the epidemic and the public's focus at different stages. Descriptive analysis of the basic information of the rumors was conducted using SPSS for Windows, version 24.0.0 (IBM Corporation). The geographic distributions of rumor sources and refuters were graphed using the pyecharts package in Python version 2.7. In addition, the cumulative number of cases and rumors in each province was calculated. The Pearson chi-square test and Fisher exact test were performed to compare different characteristics 
of the rumors by each category across the five periods. The Spearman rank correlation coefficient was used to explore the relationship between the number of rumors and the epidemic trends if the variables did not satisfy the normal distribution. $P$ values were 2 -tailed, with statistical significance set at .05 .

\section{Results}

A total of 1943 rumors were collected from the Rumors on Weibo account in this study between January 20 and April 8, 2020 .

\section{Characteristics of Rumors According to the Five Periods}

The numbers of rumors published across the periods were 102 , $547,349,377$, and 568, respectively (Table 2). Rumors in the form of texts were predominant (1241/1943, 63.9\%), accounting for more than half of the rumors in each time period, followed by rumors in a combination of two or more formats (330/1943, $17.0 \%)$. Among the rumor-spreading platforms, chat tools were the most common $(1412 / 1943,72.7 \%)$, with $1386 / 1943$ rumors circulating in WeChat, accounting for the vast majority (98.2\%).
The proportions of the 1943 rumors circulating from Weibo $(\mathrm{n}=180,9.3 \%)$, web pages $(\mathrm{n}=162,8.3 \%)$, and other platforms $(\mathrm{n}=189,9.7 \%)$ were similar. Additionally, $19.4 \%(376 / 1943)$ and $79.1 \%(1537 / 1943)$ of the rumors were refuted by national and local agencies, respectively. Most rumors were clarified by relevant government authorities $(1250 / 1943,64.3 \%)$, followed by the news media $(628 / 1943,32.3 \%)$.

The epidemic curve and daily number of posted and refuted rumors graphed according to the key events are illustrated in Figure 2. Spearman rank coefficient analysis showed that the daily number of posted rumors was positively associated with the daily number of new confirmed cases (Spearman rank correlation coefficient $0.73, P<.001$ ). The median of the response interval between the time when the rumors were initially published and debunked was 1 day, with an IQR of 1-2. Most rumors detected were mainly concentrated between January 24 and February 7, while the majority of the refuting posts were concentrated between January 25 and February 9, with the highest daily reports of posting and refuting rumors occurring on January $25(\mathrm{n}=91)$ and February $6(\mathrm{n}=80)$, respectively. 
Table 2. Characteristics of rumors across five periods during the outbreak of COVID-19 in China (N=1943). ${ }^{\mathrm{a}} P<.001$ for all categories.

\begin{tabular}{|c|c|c|c|c|c|c|c|}
\hline \multirow[t]{2}{*}{ Characteristic } & \multicolumn{5}{|c|}{ Time periods (2020) } & \multirow[t]{2}{*}{ Total $(\mathrm{N}=1943)$} & \multirow{2}{*}{$\chi^{2}(d f)$} \\
\hline & $\begin{array}{l}\text { Jan 20-24 } \\
(n=102)\end{array}$ & $\begin{array}{l}\text { Jan } 25-F e b 4 \\
(n=547)\end{array}$ & $\begin{array}{l}\text { Feb 5-12 } \\
(\mathrm{n}=349)\end{array}$ & $\begin{array}{l}\text { Feb 13- } 26 \\
(\mathrm{n}=377)\end{array}$ & $\begin{array}{l}\text { Feb 27-Apr } \\
8(\mathrm{n}=568)\end{array}$ & & \\
\hline Format of rumor, $n(\%)$ & & & & & & & $41.6(12)$ \\
\hline Text & $69(67.6)$ & $354(64.7)$ & $228(65.3)$ & $228(76.4)$ & $362(63.7)$ & $1241(63.9)$ & \\
\hline Picture & $6(5.9)$ & $26(4.8)$ & $18(5.2)$ & $17(4.5)$ & $47(8.3)$ & $114(5.9)$ & \\
\hline Multimedia $^{\mathrm{b}}$ & $6(5.9)$ & $85(15.5)$ & $38(10.9)$ & $41(10.9)$ & $88(15.5)$ & $258(13.3)$ & \\
\hline Combination $^{\mathrm{c}}$ & $21(20.6)$ & $82(15.0)$ & $65(18.6)$ & $91(24.1)$ & $71(12.5)$ & $330(17.0)$ & \\
\hline Initial platform of rumor posting, $n(\%)$ & & & & & & & $127.6(12)$ \\
\hline Chat tools ${ }^{\mathrm{d}}$ & $75(73.5)$ & $453(82.8)$ & $270(77.4)$ & $279(74.0)$ & $335(59.0)$ & $1412(72.7)$ & \\
\hline Weibo & $15(14.7)$ & $39(7.1)$ & $41(11.7)$ & $30(8.0)$ & $55(9.7)$ & $180(9.3)$ & \\
\hline Web pages & $10(9.8)$ & $29(5.3)$ & $11(3.2)$ & $29(7.7)$ & $83(14.6)$ & $162(8.3)$ & \\
\hline Others ${ }^{\mathrm{e}}$ & $2(2.0)$ & $26(4.8)$ & $27(7.7)$ & $39(10.3)$ & $95(16.7)$ & $189(9.7)$ & \\
\hline Level of rumor refuter, $n(\%)$ & & & & & & & $61.0(8)$ \\
\hline National & $29(28.4)$ & $65(11.9)$ & $63(18.1)$ & $77(20.4)$ & $142(25.0)$ & $376(19.4)$ & \\
\hline Local & $66(64.7)$ & $478(87.4)$ & $280(80.2)$ & $295(78.2)$ & $418(73.6)$ & $1537(79.1)$ & \\
\hline Others & $7(6.9)$ & $4(0.7)$ & $6(1.7)$ & $5(1.3)$ & $8(1.4)$ & $30(1.5)$ & \\
\hline Type of rumor refuter, $\mathrm{n}(\%)$ & & & & & & & $219.5(8)$ \\
\hline Government authority & $67(65.7)$ & $466(85.2)$ & $240(68.8)$ & $217(57.6)$ & $260(45.8)$ & $1250(64.3)$ & \\
\hline News media & $25(24.5)$ & $74(13.5)$ & $101(28.9)$ & $152(40.3)$ & $276(48.6)$ & $628(32.3)$ & \\
\hline Organization, company, or individual & $10(9.8)$ & $7(1.3)$ & $8(2.3)$ & $8(2.1)$ & $32(5.6)$ & $65(3.3)$ & \\
\hline
\end{tabular}

${ }^{\mathrm{a}}$ The five periods were classified based on key events and the disease epidemic that could affect the dissemination of rumors on the internet from January 20 to April 8, 2020.

${ }^{\mathrm{b}}$ Multimedia: video, audio, and news reports.

${ }^{\mathrm{c}}$ Combination: two or three formats were combined to disseminate rumors.

${ }^{\mathrm{d}}$ Chat tools: WeChat and Tencent QQ.

${ }^{\mathrm{e}}$ Others: other platforms that could not be classified in any of the above categories, including several mobile apps such as TikTok, and platforms that could not be traced back.

\section{Characteristics of Rumors on Different Posting Platforms}

A comparison of the 1943 rumors categorized by rumor-posting platform is shown in Table 3. Text (1241/1943, 63.9\%) was the most common rumor format across different posting platforms, while the image format $(114 / 1943,5.9 \%)$ had the lowest percentage of all rumors. In addition to the texts, there were more rumors disseminated in a combination of formats on Weibo $(60 / 180,33.3 \%)$, while web pages $(54 / 162,33.3 \%)$ and others $(42 / 189,22.2 \%)$ tended to be the initial publishing platforms for rumors in multimedia format. Pearson chi-square tests indicated that there were statistically significant differences in the formats of rumors classified by platform $\left(\chi^{2}{ }_{9}=142.6\right.$, $P<.001)$. Local agencies played a large role in dispelling rumors on the rumor-spreading platforms. The rumor refuters of government authorities and news media worked in tandem and complemented each other, and together they dispelled approximately $90 \%$ of the rumors on every platform. Fisher exact tests and Pearson chi-square tests suggested that the types of rumor refuters were significantly different across the platforms $(P<.001)$. 
Table 3. Comparison of different rumor posting platforms between January 20 and April 8, 2020 (N=1943). $P<.001$ for all categories.

\begin{tabular}{|c|c|c|c|c|c|c|}
\hline \multirow[t]{2}{*}{ Classification } & \multicolumn{6}{|c|}{ Initial platform of rumor posting, $\mathrm{n}(\%)$} \\
\hline & $\begin{array}{l}\text { Chat tools }{ }^{\mathrm{a}} \\
(\mathrm{n}=1412)\end{array}$ & $\begin{array}{l}\text { Weibo } \\
(\mathrm{n}=180)\end{array}$ & $\begin{array}{l}\text { Web pages } \\
(\mathrm{n}=162)\end{array}$ & $\begin{array}{l}\text { Others }^{b} \\
(\mathrm{n}=189)\end{array}$ & Total $(\mathrm{N}=1943)$ & $\chi^{2}(d f)$ \\
\hline Format of rumor, $n(\%)$ & & & & & & $142.6(9)$ \\
\hline Texts & $941(66.6)$ & $85(47.2)$ & $81(50.0)$ & $134(70.9)$ & $1241(63.9)$ & \\
\hline Pictures & $91(6.4)$ & $11(6.1)$ & $8(4.9)$ & $4(2.1)$ & $114(5.9)$ & \\
\hline Multimedia $^{\mathrm{c}}$ & $138(9.8)$ & $24(13.3)$ & $54(33.3)$ & $42(22.2)$ & $258(13.3)$ & \\
\hline Combination $^{\mathrm{d}}$ & $242(17 \cdot 1)$ & $60(33.3)$ & $19(11.7)$ & $9(4.8)$ & $330(17.0)$ & \\
\hline Level of rumor refuter, $n(\%)$ & & & & & & $\mathrm{N} / \mathrm{A}^{\mathrm{e}}$ \\
\hline National & $145(10.3)$ & $63(35.0)$ & $81(50.0)$ & $87(46.0)$ & $376(19.4)$ & \\
\hline Local & $1256(89 \cdot 0)$ & 109 (60.6) & $73(45.1)$ & $99(52.4)$ & $1537(79.1)$ & \\
\hline Others & $11(0.8)$ & $8(4.4)$ & $8(4.9)$ & $3(1.6)$ & $30(1.5)$ & \\
\hline Type of rumor refuter, $\mathrm{n}(\%)$ & & & & & & $180.2(6)$ \\
\hline Government authorities & $1030(72.9)$ & $87(48.3)$ & $56(34.6)$ & 77 (40.7) & $1250(64.3)$ & \\
\hline News media & $354(25.1)$ & $80(44.4)$ & 95 (58.6) & $99(52.4)$ & $628(32.3)$ & \\
\hline Organization/company/individual & $28(2.0)$ & $13(7.2)$ & $11(6.8)$ & $13(6.9)$ & $65(3.3)$ & \\
\hline
\end{tabular}

${ }^{\mathrm{a}}$ Chat tools: WeChat and Tencent QQ.

${ }^{b}$ Others: other platforms that could not be classified in any of the above categories, including several mobile apps such as TikTok, and platforms on which the source of the rumors could not be traced.

${ }^{\mathrm{c}}$ Multimedia: video, audio, and news reports.

${ }^{\mathrm{d}}$ Combination: two or three formats were combined to disseminate rumors.

${ }^{\mathrm{e}}$ N/A: not applicable ( $P$ value was calculated using Fisher exact test).

\section{Geographic Distribution of Rumor Sources and Refuters}

The cumulative numbers of confirmed cases of COVID-19 and rumors generated by province across China as of April 8, 2020, are visualized in Figure 3. The internet rumors spread more actively in the southeast regions. In particular, Hubei Province and its surrounding areas showed the highest numbers of both confirmed cases and rumors in the country. The cumulative number of confirmed cases in Guangdong Province as of April 8 was ranked second in the country, whereas rumor generation in that province was relatively low. Conversely, although
Guangxi Province had fewer cases, its number of rumors was among the highest nationwide.

The geographic distributions of the rumor sources and their corresponding refuters are graphed in Figure 4, where the arrow symbols indicate rumor-refuting locations. Beijing and Wuhan were the two main hubs of disinformation refuting during this stage of the COVID-19 epidemic. In Guangdong Province, where the epidemic was relatively severe, more rumors were refuted than spread. Except for the rumors that were clarified locally, rumors circulating within the provinces were often officially refuted by the provincial governments. 
Figure 3. Cumulative numbers of confirmed cases of COVID-19 and rumors in each region of China as of April 8, 2020.

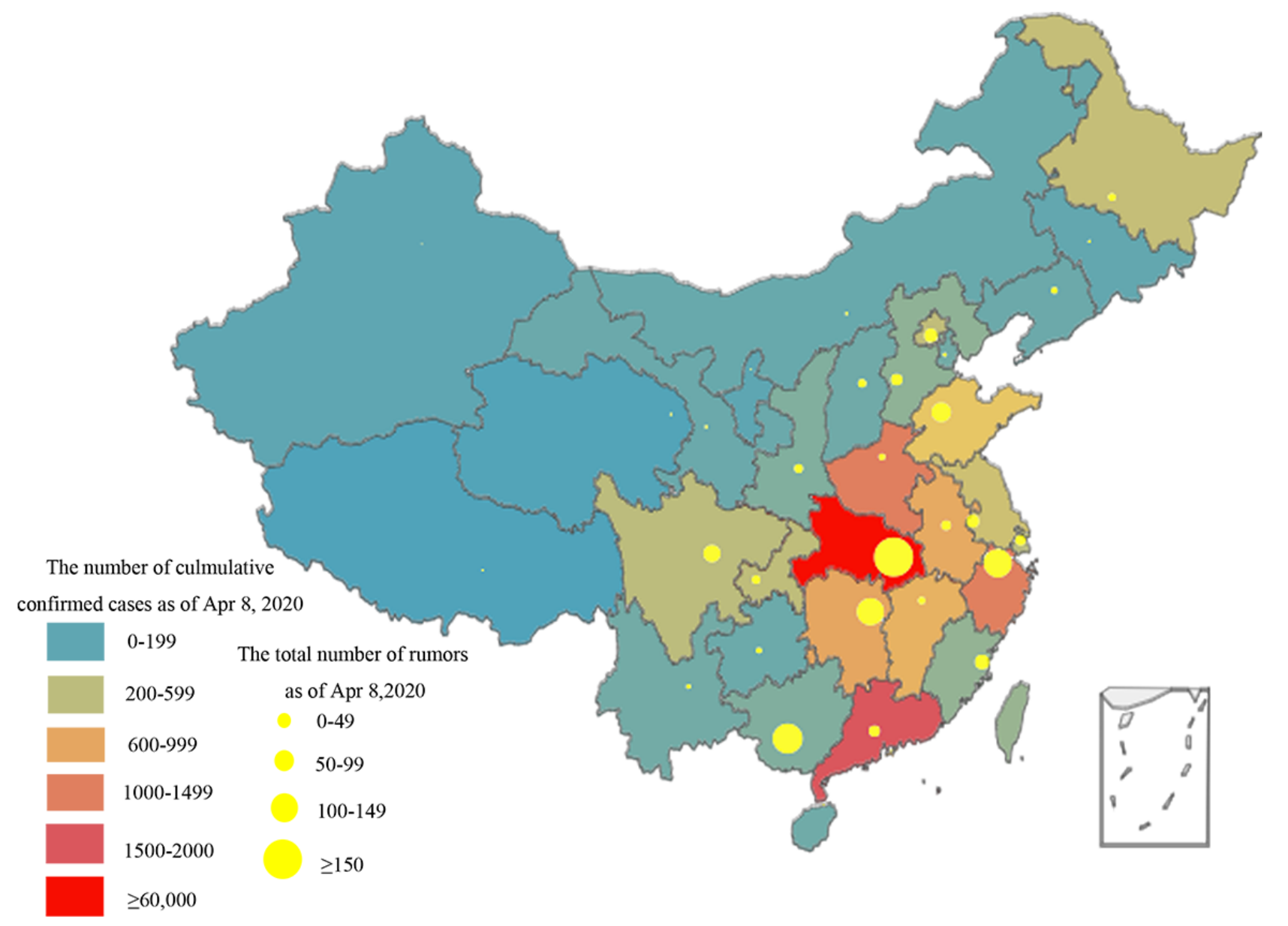


Figure 4. The geographic distributions of rumor sources and refuters during the outbreak of COVID-19 between January 20 and April 8, 2020 , in China.

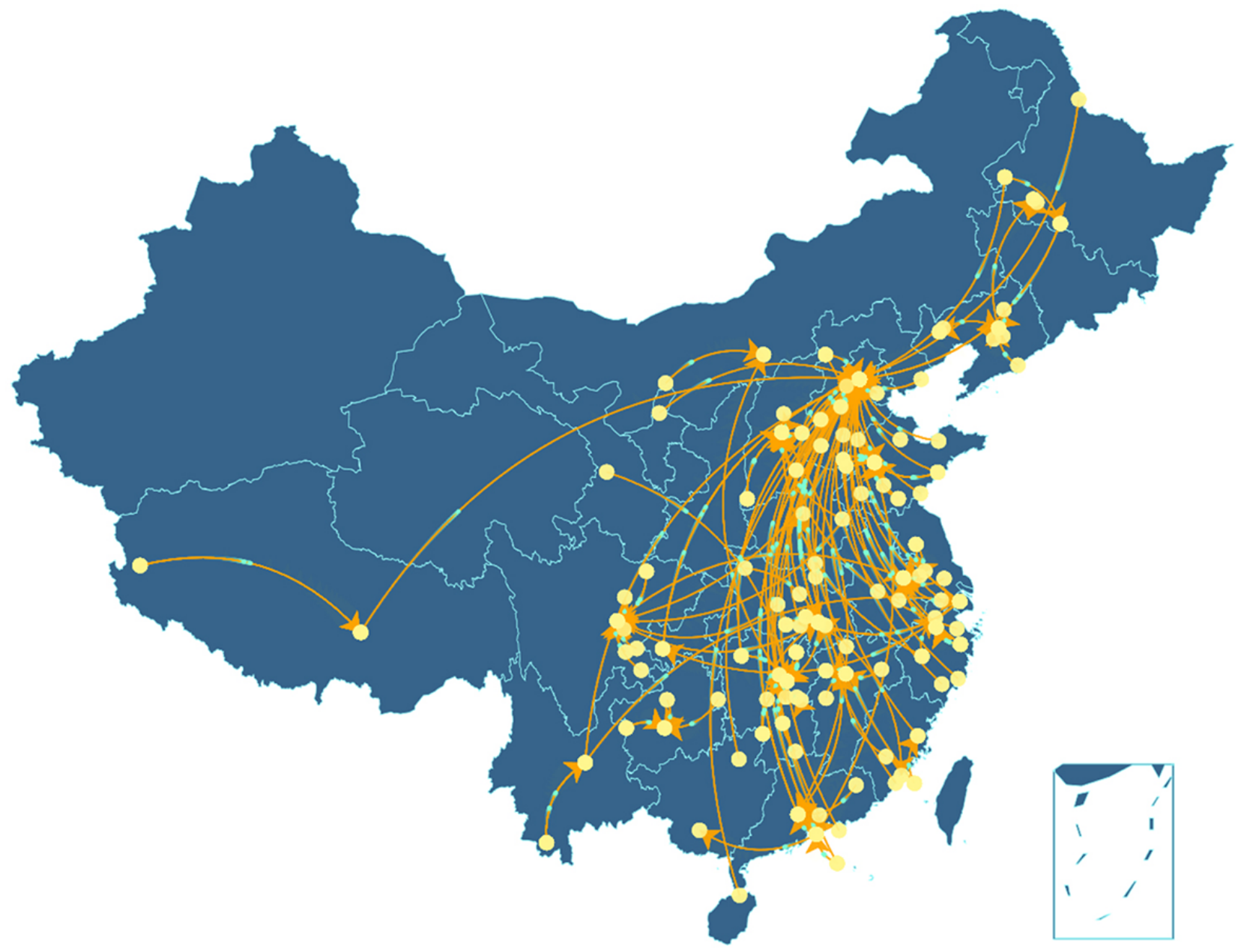

\section{General Focus and Frequent Words of Rumors During the Five Phases}

The top 100 most frequent words of the core messages of the rumors throughout the study period and different phases of the outbreak are depicted in Figure 5 (also see Multimedia Appendix 1 for a description of the evolution trends of the top 10 most frequent words, excluding the search keywords, at different periods during the outbreak). The average length of the textual rumors was nearly 19 characters. Overall, 冠状病毒 (coronavirus) and 肺炎 (pneumonia) were the two most common words included in the rumor core message. A majority of the words, such as 病毒 (virus), 新型 (novel), 新冠 (the Chinese abbreviation for COVID-19), and 病例 (case), were associated with COVID-19. In addition, 武汉 (Wuhan), 医院 (hospital), 小区 (residential areas), as terms related to specific locations were also frequently found in the rumors. Meanwhile, some words describing epidemic prevention and control, such as $\square$ 罩 (mask), 消毒 (disinfection), and 隔离 (quarantine), were often seen. 
Figure 5. The top 100 most frequent words in the core messages of rumors during the outbreak of COVID-19 in China: (A) during the whole study period, (B) from January 20-24, 2020, (C) from January 25 to February 4, 2020, (D) from February 5-12, 2020, (E) February 13-26, 2020, and (F) from February 27 to April 8, 2020.

(A)

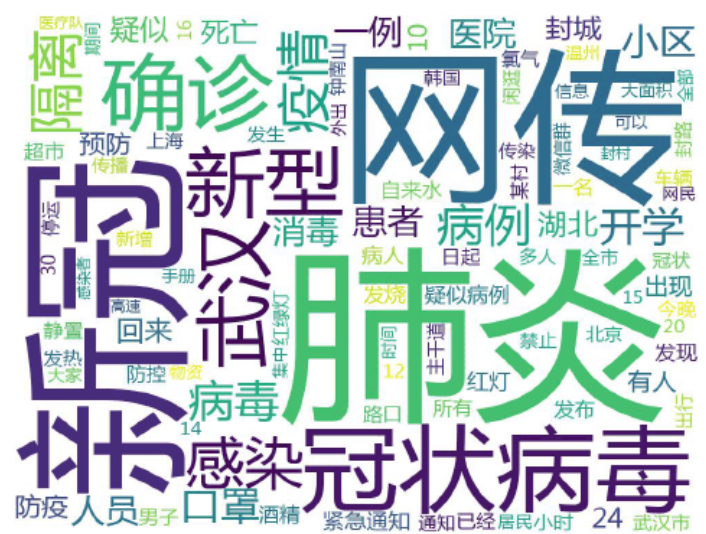

(C)

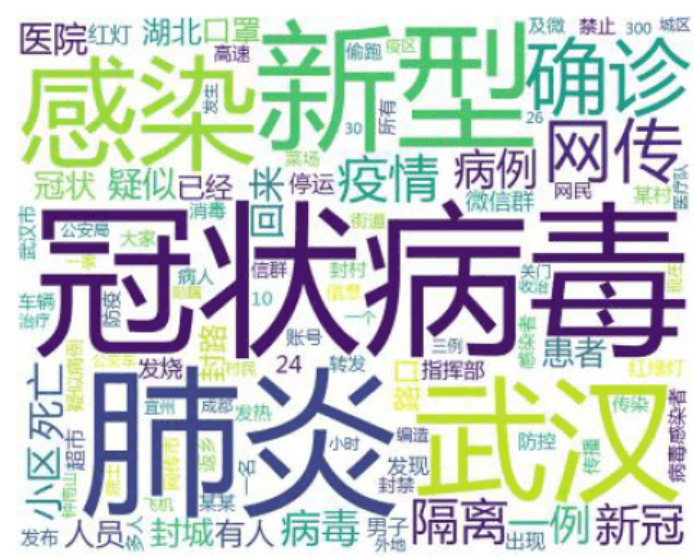

$(\mathrm{E})$

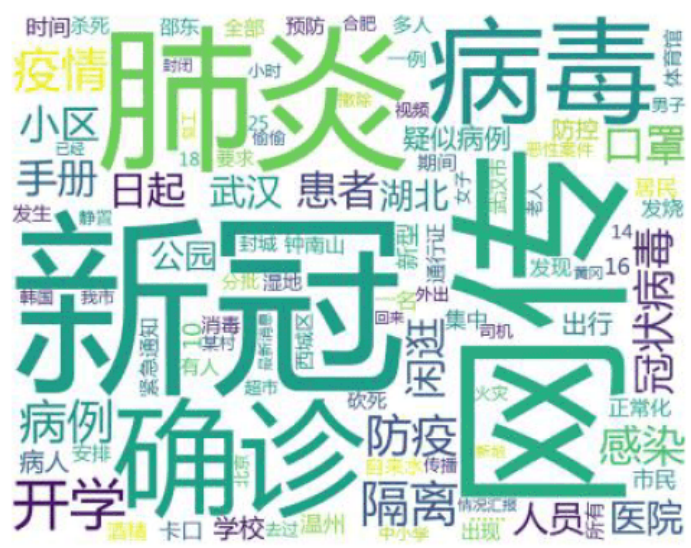

More details of the top 20 words listed according to their TF-IDF values in the major rumor messages over different periods are presented in Table 4. The top 5 words in the first and second periods were the same. However, the TF-IDF value of each of these words was different; the values in the first stage were higher than those in the second stage. By the third period, 网传 (sourced from internet) had become the top word, while the words 消毒 (disinfection) and 口罩 (mask) had replaced 武汉
(B)

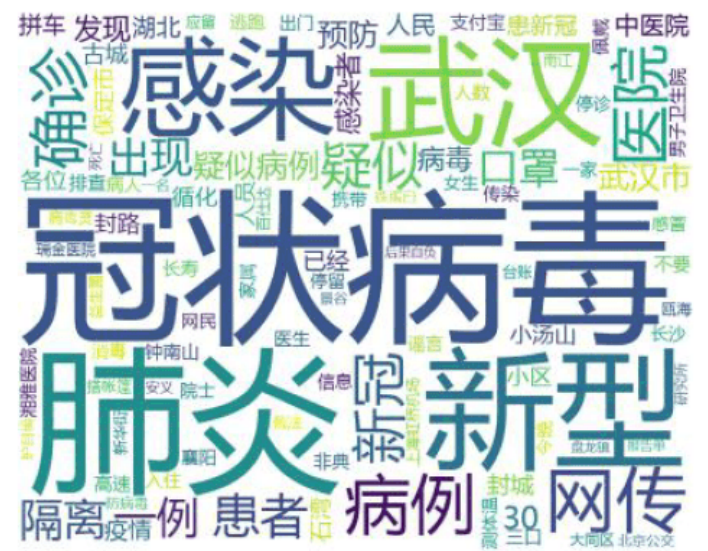

(D)

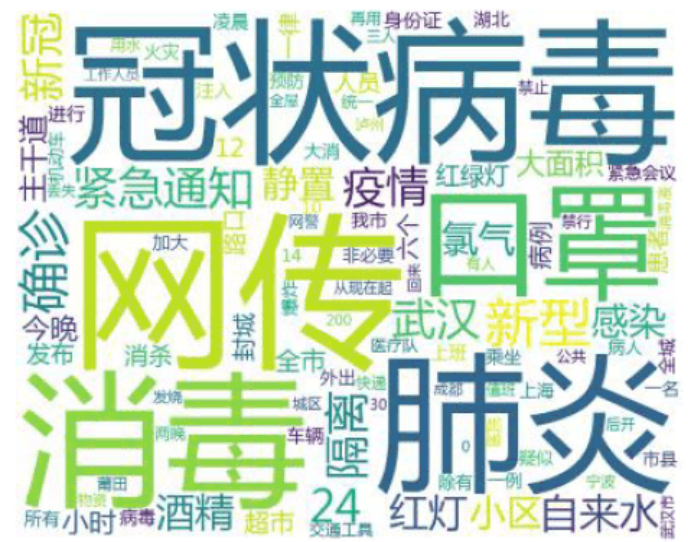

(F)

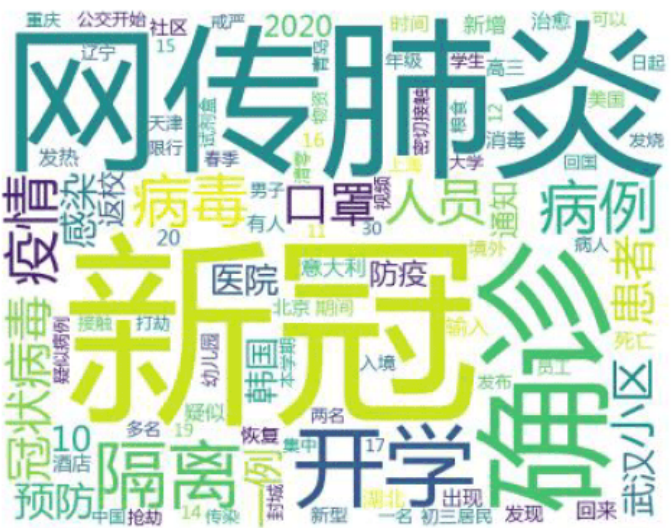

(Wuhan) and 感染 (infection) as the fourth and fifth most common words, respectively. In contrast to similar rumors about the epidemic at the other stages, disinformation related to 开学 (schools reopen) began to grow during the fourth and fifth periods. Moreover, as the outbreak of COVID-19 increased outside China, rumors of foreign epidemic situations increased as well. 
Table 4. The top 20 keywords in rumors across five periods during the outbreak of COVID-19 in China. ${ }^{\text {a }}$

\begin{tabular}{|c|c|c|c|c|c|c|c|c|c|c|}
\hline \multirow[t]{3}{*}{ Rank $^{b}$} & \multicolumn{10}{|c|}{ Time periods (2020) } \\
\hline & \multicolumn{2}{|l|}{ Jan $20-24$} & \multicolumn{2}{|l|}{ Jan 25-Feb 4} & \multicolumn{2}{|l|}{ Feb 5-12 } & \multicolumn{2}{|l|}{ Feb 13-26 } & \multicolumn{2}{|l|}{ Feb 27-Apr 8} \\
\hline & Keyword & $\begin{array}{l}\text { TF-IDF } \\
\text { value }\end{array}$ & Keyword & $\begin{array}{l}\text { TF-IDF } \\
\text { value }\end{array}$ & Keyword & $\begin{array}{l}\text { TF-IDF } \\
\text { value }\end{array}$ & Keyword & $\begin{array}{l}\text { TF-IDF } \\
\text { value }\end{array}$ & Keyword & $\begin{array}{l}\text { TF-IDF } \\
\text { value }\end{array}$ \\
\hline 1 & $\begin{array}{l}\text { 冠状病毒 } \\
\text { (coronavirus) }\end{array}$ & 0.480 & $\begin{array}{l}\text { 冠状病毒 } \\
\text { (coronavirus) }\end{array}$ & 0.256 & $\begin{array}{l}\text { 网传 (source } \\
\text { from internet) }\end{array}$ & 0.157 & $\begin{array}{l}\text { 新冠 (novel } \\
\text { corona) }\end{array}$ & 0.251 & $\begin{array}{l}\text { 新冠 (novel } \\
\text { corona) }\end{array}$ & 0.283 \\
\hline 2 & $\begin{array}{l}\text { 肺炎 (pneumo- } \\
\text { nia) }\end{array}$ & 0.434 & $\begin{array}{l}\text { 肺炎 (pneumo- } \\
\text { nia) }\end{array}$ & 0.237 & $\begin{array}{l}\text { 冠状病毒 } \\
\text { (coronavirus) }\end{array}$ & 0.132 & $\begin{array}{l}\text { 网传 (source } \\
\text { from internet) }\end{array}$ & 0.219 & $\begin{array}{l}\text { 肺炎 (pneumo- } \\
\text { nia) }\end{array}$ & 0.187 \\
\hline 3 & 新型 (novel) & 0.294 & 新型 (novel) & 0.182 & $\begin{array}{l}\text { 肺炎(pneumo- } \\
\text { nia) }\end{array}$ & 0.123 & $\begin{array}{l}\text { 肺炎(pneumo- } \\
\text { nia) }\end{array}$ & 0.149 & $\begin{array}{l}\text { 网传 (source } \\
\text { from internet) }\end{array}$ & 0.163 \\
\hline 4 & 武汉 (Wuhan) & 0.284 & 武汉 (Wuhan) & 0.167 & $\begin{array}{l}\text { 消毒 (disinfec- } \\
\text { tion) }\end{array}$ & 0.119 & $\begin{array}{l}\text { 确诊 (con- } \\
\text { firmed diagno- } \\
\text { sis) }\end{array}$ & 0.112 & $\begin{array}{l}\text { 确诊 (con- } \\
\text { firmed diagno- } \\
\text { sis) }\end{array}$ & 0.122 \\
\hline 5 & 感染 (infection) & 0.235 & 感染 (infection) & 0.163 & 口罩 (mask) & 0.085 & 病毒 (virus) & 0.100 & $\begin{array}{l}\text { 开学 (schools } \\
\text { reopen) }\end{array}$ & 0.117 \\
\hline 6 & $\begin{array}{l}\text { 网传 (source } \\
\text { from Internet) }\end{array}$ & 0.151 & $\begin{array}{l}\text { 确诊 (con- } \\
\text { firmed diagno- } \\
\text { sis) }\end{array}$ & 0.126 & 新型 (novel) & 0.085 & $\begin{array}{l}\text { 开学 (schools } \\
\text { reopen) }\end{array}$ & 0.099 & $\begin{array}{l}\text { 隔离 (quaran- } \\
\text { tine) }\end{array}$ & 0.074 \\
\hline 7 & 病例 (case) & 0.127 & $\begin{array}{l}\text { 网传 (source } \\
\text { from internet) }\end{array}$ & 0.116 & $\begin{array}{l}\text { 确诊 (con- } \\
\text { firmed diagno- } \\
\text { sis) }\end{array}$ & 0.083 & $\begin{array}{l}\text { 隔离 (quaran- } \\
\text { tine) }\end{array}$ & 0.073 & 病例 (case) & 0.070 \\
\hline 8 & $\begin{array}{l}\text { 确诊 (con- } \\
\text { firmed diagno- } \\
\text { sis) }\end{array}$ & 0.112 & $\begin{array}{l}\text { 疫情 (epidemic } \\
\text { situation) }\end{array}$ & 0.102 & $\begin{array}{l}\text { 紧急通知 (ur- } \\
\text { gent notice) }\end{array}$ & 0.079 & $\begin{array}{l}\text { 疫情 (epidem- } \\
\text { ic situation) }\end{array}$ & 0.067 & 病毒 (virus) & 0.069 \\
\hline 9 & 医院 (hospital) & 0.111 & $\begin{array}{l}\text { 隔离 (quaran- } \\
\text { tine) }\end{array}$ & 0.095 & $\begin{array}{l}\text { 新冠 (novel } \\
\text { corona) }\end{array}$ & 0.076 & 病例 (case) & 0.067 & $\begin{array}{l}\text { 疫情 (epidemic } \\
\text { situation) }\end{array}$ & 0.065 \\
\hline 10 & $\begin{array}{l}\text { 新冠 (novel } \\
\text { corona) }\end{array}$ & 0.090 & $\begin{array}{l}\text { 新冠 (novel } \\
\text { corona) }\end{array}$ & 0.077 & 武汉(Wuhan) & 0.075 & $\begin{array}{l}\text { 防疫 (anti-epi- } \\
\text { demic) }\end{array}$ & 0.063 & $\begin{array}{l}\text { 人员 (person- } \\
\text { nel) }\end{array}$ & 0.052 \\
\hline 11 & $\begin{array}{l}\text { 疑似 (suspect- } \\
\text { ed) }\end{array}$ & 0.081 & 病例 (case) & 0.068 & $\begin{array}{l}\text { 隔离 (quaran- } \\
\text { tine) }\end{array}$ & 0.075 & $\begin{array}{l}\text { 感染 (infec- } \\
\text { tion) }\end{array}$ & 0.056 & $\begin{array}{l}\text { 冠状病毒 } \\
\text { (coronavirus) }\end{array}$ & 0.046 \\
\hline 12 & 患者 (patients) & 0.072 & 一例 (one) & 0.065 & $\begin{array}{l}\text { 疫情 (epidem- } \\
\text { ic situation) }\end{array}$ & 0.067 & $\begin{array}{l}\text { 冠状病毒 } \\
\text { (coronavirus) }\end{array}$ & 0.055 & 口罩 (mask) & 0.045 \\
\hline 13 & $\begin{array}{l}\text { 隔离 (quaran- } \\
\text { tine) }\end{array}$ & 0.062 & 病毒 (virus) & 0.062 & $\begin{array}{l}\text { 自来水 (piped } \\
\text { water) }\end{array}$ & 0.067 & 口罩 (mask) & 0.054 & $\begin{array}{l}\text { 小区 (residen- } \\
\text { tial areas) }\end{array}$ & 0.044 \\
\hline 14 & 出现 (appear) & 0.058 & 死亡 (death) & 0.059 & $\begin{array}{l}\text { 红灯 (red } \\
\text { light) }\end{array}$ & 0.063 & $\begin{array}{l}\text { 闲逛 (hang } \\
\text { out) }\end{array}$ & 0.053 & 患者 (patients) & 0.043 \\
\hline 15 & 一例 (one) & 0.058 & $\begin{array}{l}\text { 小区 (residen- } \\
\text { tial areas) }\end{array}$ & 0.055 & $\begin{array}{l}\text { 酒精 (ethyl al- } \\
\text { cohol) }\end{array}$ & 0.062 & $\begin{array}{l}\text { 患者 (pa- } \\
\text { tients) }\end{array}$ & 0.052 & $\begin{array}{l}\text { 预防 (preven- } \\
\text { tion) }\end{array}$ & 0.042 \\
\hline 16 & 口罩 (mask) & 0.057 & 回来 (back) & 0.052 & $\begin{array}{l}\text { 感染 (infec- } \\
\text { tion) }\end{array}$ & 0.057 & $\begin{array}{l}\text { 手册 (hand- } \\
\text { book) }\end{array}$ & 0.051 & 一例 (one) & 0.041 \\
\hline 17 & $\begin{array}{l}\text { 疑似病例 (sus- } \\
\text { pected cases) }\end{array}$ & 0.047 & 医院 (hospital) & 0.049 & $\begin{array}{l}\text { 静置 (placed } \\
\text { still) }\end{array}$ & 0.055 & $\begin{array}{l}\text { 小区 (residen- } \\
\text { tial areas) }\end{array}$ & 0.051 & 感染 (infection) & 0.038 \\
\hline 18 & $\begin{array}{l}\text { 预防 (preven- } \\
\text { tion) }\end{array}$ & 0.043 & $\begin{array}{l}\text { 疑似 (suspect- } \\
\text { ed) }\end{array}$ & 0.046 & $\begin{array}{l}\text { 氯气 (chlo- } \\
\text { rine) }\end{array}$ & 0.054 & $\begin{array}{l}\text { 日起 (as from } \\
\text { today) }\end{array}$ & 0.045 & 医院 (hospital) & 0.030 \\
\hline 19 & 发现 (find) & 0.039 & 患者 (patients) & 0.041 & $\begin{array}{l}\text { 小区 (residen- } \\
\text { tial areas) }\end{array}$ & 0.054 & $\begin{array}{l}\text { 医院 (hospi- } \\
\text { tal) }\end{array}$ & 0.042 & 武汉 (Wuhan) & 0.029 \\
\hline 20 & 病毒 (virus) & 0.037 & $\begin{array}{l}\text { 封城 (lock- } \\
\text { down) }\end{array}$ & 0.040 & $\begin{array}{l}\text { 大面积 (large } \\
\text { tracts of land) }\end{array}$ & 0.053 & 武汉(Wuhan) & 0.041 & 韩国 (Korea) & 0.028 \\
\hline
\end{tabular}

${ }^{\mathrm{a}}$ The five periods were classified based on key events and the disease epidemic that could affect the dissemination of rumors on the internet from January 20 to April 8, 2020.

${ }^{\mathrm{b}}$ Keywords are ranked according to the TF-IDF values of the words from high to low.

${ }^{\mathrm{c}}$ TD-IDF: term frequency-inverse document frequency. 


\section{Discussion}

\section{Principal Findings}

Based on the official Sina Weibo rumor-refuting platform, nearly 2000 rumors that spread over the internet during the COVID-19 epidemic in China between January 20 and April 8, 2020, were investigated. This is the first domestic research to analyze the distribution, characteristics, spreading trend, and most frequent words of rumors related to the epidemic situation, which will be propitious to provide a scientific reference for the prevention and control of network rumors during unexpected events in the future.

During the study period, the median of the response interval was 1 day, indicating the timeliness of the rumor-refuting measures conducted by the Chinese government during the COVID-19 outbreak. In general, the number of rumors and refuted rumors in the first and second periods of the epidemic showed rapid growth, while both showed fluctuating declining trends in the latter three periods. Notably, after the announcement of the Wuhan lockdown, the rumor posts reached their first peak within three days, suggesting that the rapid rise in the number of rumors over the early period has a strong link with the emergence of landmark events. At this stage, due to the sudden outbreak of COVID-19, the etiology and trend of the disease were totally unclear, and the monitoring mechanism for identifying and refuting disinformation had not yet been perfected; thus, the old rumors were not quickly clarified, while new rumors appeared in rapid succession [26]. The new and old rumors intertwined to reach the peak of rumor growth, obfuscating the truth and increasing the difficulty of epidemic prevention and control [27]. By the middle of the epidemic period, most people had developed a preliminary understanding of the disease after obtaining more official information. At this stage, the rumors were less related to symbolic events and were mainly affected by the trend of the epidemic situation, fluctuating with the increase or decrease in the number of cases. Finally, by the time the disease was under control, most people had grasped a more rational understanding of the situation, with the anxiety and tension over the uncertainties greatly alleviated, leading to a decrease of the number of rumors and their corresponding clarifications. Therefore, the early stages of public emergencies, especially new infectious diseases, are the critical period for web-based surveillance of public response, risk communication, and timely release of information from credible sources, as reflected in a study on avian influenza A (H7N9) [28]. Moreover, risk communication will promote community engagement, decrease rumors to maintain social stability, and reduce threats to public health [29]. Intensive information communication with reference to hot topics of rumors may buy time to control outbreaks and reduce the risk of transmission to humans [30,31]. Additionally, transparent sharing of information in time, particularly of adverse information, and projecting uncertainty explicitly are integral parts of the management of large-scale epidemics and other emergencies [32]. Moreover, during the period of steady decline, continuous internet surveillance of rumors is still required.
Different characteristics of the rumors were analyzed in this study; it was found that internet rumors in the early stage of the epidemic were mainly disseminated in text format, most commonly in the WeChat chat tool. More processed and visualized rumors (eg, in the formats of pictures and multimedia) emerged over the later stages, while the number of rumors increased on other platforms, such as Weibo and web pages. The difference in the main formats of rumor dissemination among different platforms may be related to the openness and information screening mechanisms of each platform. In recent years, WeChat has rapidly become the main social platform in China due to its convenience and accessibility. Compared to other social media, WeChat is a social tool based on realistic relationships and closed-loop communication in a relatively private space, implying the reliability and authenticity of information and invisibly increasing the influence of rumors $[33,34]$. Therefore, when false news circulates, WeChat lacks self-correction ability due to the trust among acquaintances, and it is also more difficult to completely convince WeChat users that a rumor is false even with rumor-dispelling messages on the internet. However, Weibo and web pages are more open and diverse; uncertain information can be questioned, corroborated, corrected, and supplemented through user-produced content, constantly discarding false information and approaching the truth in positive interactions [35,36]. Moreover, Weibo has established an increasingly comprehensive account for refuting rumors [19]. Eventually, through the questioning of netizens, inaccurate information is replaced by the truth. In recent years, WeChat and other platforms have also taken measures to combat rumors [37]. However, the dissemination of refuting information on WeChat is restricted, mainly because it cannot reach the level of interpersonal communication, leading to small-scale transmission; thus, it can only continue to be shown "to people who do not believe rumors" [38]. Thus, a more comprehensive mechanism to encourage the dissemination of rumor-dispelling information should be developed by relevant departments in the future, accelerating the spread of credible information on WeChat and extending the influence of these departments at the same time.

Analysis of the refuters of rumors showed that during the initial outbreak of COVID-19, rumors were likely to be more nationally focused because they were relatively few in number, and the national-level rumor refuting agencies played a stronger role. When the rumors gradually started spreading locally, local authorities increased their rumor-refuting efforts; combined with the increasing enhancement of self-purification of social media, this eased the pressure on government agencies [28]. Similarly, due to the small scope and influence of rumor spread in chat tools, most were clarified by local government authorities. In contrast, rumors circulating in Weibo elicited more involvement and intervention from higher-level authorities, indicating a larger impact. These findings highlight the significance of coordinating the roles of central and local agencies in the establishment of mechanisms for refuting rumors, improving the feedback mechanisms, and maximizing the self-purification ability of social media.

According to the distribution map of the rumors, Hubei Province was the most active area for rumor breeding, which may be 
related to its highly severe epidemic situation. In this study, locations with more cases were likely to generate more rumors, mainly including cities around Hubei, such as Zhejiang and Hunan. However, rumors also circulated in larger quantities in provinces with lower case numbers, such as Guangxi. Accordingly, the timely identification of rumors in regions less affected by public health emergencies is of equal importance to constant internet surveillance in areas that are more severely affected. The cross-regional rumor-refuting plot shows that Beijing was the critical center for rumor clarification. Shanghai and the provincial capitals of Guangzhou, Hunan, Sichuan, and Zhejiang also played vital roles in dispelling rumors during the epidemic, reflecting to some extent that large cities are political and media centers [39].

The high-frequency words in different periods indicated that in the pre-epidemic period, the rumors were mainly related to the disease itself, with numerous descriptions of COVID-19 contained in the core message of the rumors. In the middle of the epidemic, the rumors gradually began to be associated with prevention and control measures due to the official announcement of epidemic initiatives published by departmental agencies. When the domestic epidemic had been effectively controlled, false information about measures such as school reopening and traffic resumption spread across each region, suggesting that people gradually paid more attention to information related to policy adjustment during this period compared to the previous stages [26]. The word 网传 (source from internet) was frequently included in the titles of rumors. The word 确诊 (confirmed diagnosis) continued to appear frequently across different periods, even when the number of daily new confirmed cases had decreased since the third period. Further, when the words 确诊 (confirmed diagnosis) and 病例 (case) were combined in a rumor, the title usually took the form of "multiple cases have been confirmed in a certain place"; thus, the rumors were in a "storytelling" form that was immersive and highly convincing to readers. Such rumors have also been reported in other studies on infectious diseases [28], providing a reference for accurate identification of rumors in the future.

\section{Limitations}

There were several limitations to this study. First, this study was a retrospective analysis based on information extracted from an official rumor-refuting account, and it was difficult to avoid omitting some detailed information. In some cases, we could not trace or confirm the platforms or geographic locations where the rumors were initially published. Second, because the information of rumors in this study was refined, the emoticons and function words in the original text were not addressed; this could be considered in future research. Third, not all the rumors could be refuted on this account; instead, the most socially influential rumors were included, which could lead to information loss from the less influential rumors.

\section{Conclusions}

Our findings indicate the significance of timely management of and responses to internet rumors during major public crises. In this wave of the COVID-19 outbreak, authorities have taken effective measures to quickly dispel rumors; however, more effort could be made to better address the rumors. WeChat and other chat tools were found to be the most common origins of rumors, suggesting that the early detection and debunking mechanisms of rumors should be strengthened in closed-loop communication environments. In the early stages of the event, authorities should focus on rumors in the form of texts but should also pay more attention to other forms such as multimedia as the event progresses. The words most frequently included in the core messages of the rumors varied over different periods, which may be related to the disease itself, prevention and control measures, and social recovery; this highlights that targeted policy adjustments and timely release of official information in different phases of the outbreak should be required to prevent dissemination of internet rumors. Spread of rumors across borders needs to be controlled regardless of the intensity of the epidemic in the area. Local and national authorities should strengthen joint communication and collaboration in refuting rumors and establish a cooperative refuting mechanism based on the division of functions.

\section{Acknowledgments}

This work was supported by Nation-Zhejiang Cooperating Project (grant number WKJ-2J-1001), Zhejiang Provincial Science and Public Welfare (grant number LGF19H260004), and Zhejiang Provincial Medical and Health Project (grant number 2021KY618).

\section{Authors' Contributions}

$\mathrm{BC}$, JP, and JMJ designed the study. BC, XYC, and KL analyzed the data, interpreted the results, produced the figures, and prepared the manuscript with support from JP and JMJ. BC and XYC contributed to the manuscript writing. JP and JMJ supervised the project. All authors contributed to report writing and approved the final manuscript.

\section{Conflicts of Interest}

None declared.

\section{Multimedia Appendix 1}

The evolution trends of the top 10 buzzwords (excluding the search keywords) at different periods during the outbreak. [PNG File, $281 \mathrm{~KB}-$ Multimedia Appendix 1]

\section{References}


1. Clinical management of severe acute respiratory infection when novel coronavirus (2019-nCoV) infection is suspected: interim guidance. World Health Organization. 2020 Jan 28. URL: https://apps. who.int/iris/bitstream/handle/10665/330893/ WHO-nCoV-Clinical-2020.3-eng.pdf?sequence $=1$ \&isAllowed =y [accessed 2020-04-23]

2. Hui DS, I Azhar E, Madani TA, Ntoumi F, Kock R, Dar O, et al. The continuing 2019-nCoV epidemic threat of novel coronaviruses to global health - the latest 2019 novel coronavirus outbreak in Wuhan, China. Int J Infect Dis 2020 Feb;91:264-266 [FREE Full text] [doi: 10.1016/j.ijid.2020.01.009] [Medline: $\underline{\text { 31953166] }}$

3. Chen N, Zhou M, Dong X, Qu J, Gong F, Han Y, et al. Epidemiological and clinical characteristics of 99 cases of 2019 novel coronavirus pneumonia in Wuhan, China: a descriptive study. Lancet 2020 Feb 15;395(10223):507-513. [doi: 10.1016/S0140-6736(20)30211-7] [Medline: 32007143]

4. Coronavirus disease (COVID-19) Situation Report - 163. World Health Organization. 2020 Jul 01. URL: https://www. who.int/docs/default-source/coronaviruse/situation-reports/20200701-covid-19-sitrep-163.pdf?sfvrsn=c202f05b 2 [accessed 2020-07-02]

5. Barrelet C, Bourrier M, Burton-Jeangros C, Schindler M. Unresolved issues in risk communication research: the case of the H1N1 pandemic (2009-2011). Influenza Other Respir Viruses 2013 Sep 27;7 Suppl 2:114-119 [FREE Full text] [doi: 10.1111/irv.12090] [Medline: 24034495]

6. Takayasu M, Sato K, Sano Y, Yamada K, Miura W, Takayasu H. Rumor diffusion and convergence during the 3.11 earthquake: a Twitter case study. PLoS One 2015 Apr 1;10(4):e0121443 [FREE Full text] [doi: 10.1371/journal.pone.0121443] [Medline: 25831122]

7. Mocanu D, Rossi L, Zhang Q, Karsai M, Quattrociocchi W. Collective attention in the age of (mis)information. Comput Hum Behav 2015 Oct;51:1198-1204. [doi: 10.1016/j.chb.2015.01.024]

8. Global Risks 2013. World Economic Forum. URL: http://www3.weforum.org/docs/WEF GlobalRisks Report 2013.pdf [accessed 2020-08-04]

9. Huanqiu NW. Drinking spirit can prevent the infection of COVID-19. Webpage in Chinese. Huanqiu News Website. URL: https://china.huanqiu.com/article/9CaKrnKp2dt [accessed 2020-09-21]

10. Li J, Xie Y. Research on the influencing factors of online public opinion: an empirical analysis based on 10,600 public opinion events from 2010-2018. Article in Chinese. Journalism and Mass Communication Monthly 2020(2):37-45.

11. Zhang X, Li D, Xie G. Research on the participatory roles of media, netizens, and government in public opinion events: an empirical analysis of 3600 public opinion events. Article in Chinese. Journalism and Mass Communication Monthly 2018;6:56-63. [doi: 10.15897/j.cnki.cn51-1046/g2.2018.06.008]

12. Tchuenche JM, Dube N, Bhunu CP, Smith RJ, Bauch CT. The impact of media coverage on the transmission dynamics of human influenza. BMC Public Health 2011 Feb 25;11(S1). [doi: 10.1186/1471-2458-11-s1-s5]

13. Ma S. Analysis of rumor spreading in the microblog context of breaking events. Article in Chinese. Journalism Knowledge 2011;9:63-65.

14. Zeng R, Zhu D. A model and simulation of the emotional contagion of netizens in the process of rumor refutation. Sci Rep 2019 Oct 02;9(1):14164 [FREE Full text] [doi: 10.1038/s41598-019-50770-4] [Medline: $\underline{31578405]}$

15. Su Z, Li Y. Unexpected Public Health Event Calls for the Mechanism of Crisis Management in Chinese. Chinese Health Service Management 2003(9):519-520.

16. Eysenbach G. Infodemiology and infoveillance tracking online health information and cyberbehavior for public health. Am J Prev Med 2011 May;40(5 Suppl 2):S154-S158. [doi: 10.1016/j.amepre.2011.02.006] [Medline: 21521589]

17. Eysenbach G. Infodemiology: tracking flu-related searches on the web for syndromic surveillance. AMIA Annu Symp Proc 2006:244-248 [FREE Full text] [Medline: 17238340]

18. 1st WHO Infodemiology Conference. World Health Organization. 2020. URL: https://www.who.int/news-room/events/ detail/2020/06/30/default-calendar/1st-who-infodemiology-conference [accessed 2020-07-01]

19. Official Account to Refute Rumors. Webpage in Chinese. Sina Weibo. URL: https://weibo.com/ weibopiyao?from=myfollow all [accessed 2020-04-11]

20. Pan A, Liu L, Wang C, Guo H, Hao X, Wang Q, et al. Association of public health interventions with the epidemiology of the COVID-19 outbreak in Wuhan, China. JAMA 2020 May 19;323(19):1915-1923 [FREE Full text] [doi: 10.1001/jama.2020.6130] [Medline: $\underline{\text { 32275295] }}$

21. Announcement No. 1. Webpage in Chinese. National Health Commission of the People's Republic of China. 2020 Jan 21. URL: http://www.gov.cn/xinwen/2020-01/21/content 5471158.htm [accessed 2020-05-13]

22. Announcement of the novel coronavirus prevention and control command in Wuhan in Chinese. National Health Commission of the People's Republic of China. URL: http://www.gov.cn/xinwen/2020-01/23/content_5471853.htm [accessed 2020-05-13]

23. National and global distribution of COVID-19 epidemic. Webpage in Chinese. Chinese Center for Disease Control and Prevention. URL: http://2019ncov.chinacdc.cn/2019-nCoV/index.html [accessed 2020-05-13]

24. Update information on COVID-19 as of February 12, 2020. Webpage in Chinese. National Health Commission of the People's Republic of China. 2020 Feb 12. URL: http://www.gov.cn/xinwen/2020-02/13/content 5478244.htm [accessed 2020-05-13]

25. Wuhan lifted its lockdown. Webpage in Chinese. Government of Hubei. 2020 Apr 08. URL: http://www.hubei.gov.cn/ 2019/tpyw/202004/t20200408 2207205.shtml [accessed 2020-05-13] 
26. Wang C, Yu Y. The stage characteristics of rumors spread in the epidemic of COVID-19 and its countering strategies. Article in Chinese. China Newspaper Industry 2020 Apr(7):16-19.

27. Sun Y. The communication analysis of network rumor: taking the Japan Earthquake and Wenzhou Motor Car Accident as examples. Article in Chinese. Press Circles 2012(2):47-52.

28. Gu H, Chen B, Zhu H, Jiang T, Wang X, Chen L, et al. Importance of internet surveillance in public health emergency control and prevention: evidence from a digital epidemiologic study during avian influenza A H7N9 outbreaks. J Med Internet Res 2014 Jan 17;16(1):e20 [FREE Full text] [doi: 10.2196/jmir.2911] [Medline: 24440770]

29. Fagherazzi G, Goetzinger C, Rashid MA, Aguayo GA, Huiart L. Digital health strategies to fight COVID-19 worldwide: challenges, recommendations, and a call for papers. J Med Internet Res 2020 Jun 16;22(6):e19284 [FREE Full text] [doi: 10.2196/19284] [Medline: 32501804]

30. Gu Y, Chen F, Liu T, Lv X, Shao Z, Lin H, et al. Early detection of an epidemic erythromelalgia outbreak using Baidu search data. Sci Rep 2015 Jul 28;5:12649 [FREE Full text] [doi: 10.1038/srep12649] [Medline: 26218589]

31. Chen B, Zhang JM, Jiang Z, Shao J, Jiang T, Wang Z, et al. Media and public reactions toward vaccination during the 'hepatitis B vaccine crisis' in China. Vaccine 2015 Apr 08;33(15):1780-1785. [doi: 10.1016/j.vaccine.2015.02.046] [Medline: 25731787]

32. Communicating risk in public health emergencies: a WHO guideline for emergency risk communication (ERC) policy and practice. World Health Organization. 2018. URL: https://apps.who.int/iris/bitstream/handle/10665/259807/9789241550208eng. pdf:jsessionid=D6796FA0ECAD7D6A4E4C5456A762BDB2?sequence=2 [accessed 2020-06-18]

33. Zheng A. The Communication characteristics and governance measures of rumors in the WeChat moments. Article in Chinese. New Media Research 2015;1(12):14-15. [doi: 10.16604/j.cnki.issn2096-0360.2015.12.009]

34. Wang C. The dissemination characteristics of rumors in WeChat moments and its response atrategies. Article in Chinese. Youth Times 2017 Apr;12:97.

35. Chen B, Shao J, Liu K, Cai G, Jiang Z, Huang Y, et al. Does eating chicken feet with pickled peppers cause avian influenza? Observational case study on Chinese social media during the avian influenza A (H7N9) outbreak. JMIR Public Health Surveill 2018 Mar 29;4(1):e32 [FREE Full text] [doi: 10.2196/publichealth.8198] [Medline: 29599109]

36. Vos SC, Buckner MM. Social Media Messages in an Emerging Health Crisis: Tweeting Bird Flu. J Health Commun 2016 Dec 31;21(3):301-308. [doi: 10.1080/10810730.2015.1064495] [Medline: 26192209]

37. Under the epidemic, how to accurately dispel rumors on domestic and international social media platforms? Webpage in Chinese. The Paper. 2020 Feb 06. URL: https://m.thepaper.cn/newsDetail forward 5776922 [accessed 2021-02-05]

38. Hu S, Dai J. The difficulty of spreading refuting information on WeChat. Article in Chinese. Journalistic Front 2017:44-45.

39. Liu K, Li L, Jiang T, Chen B, Jiang Z, Wang Z, et al. Chinese Public Attention to the Outbreak of Ebola in West Africa: Evidence from the Online Big Data Platform. Int J Environ Res Public Health 2016 Aug 04;13(8):780 [FREE Full text] [doi: 10.3390/ijerph13080780] [Medline: 27527196]

\section{Abbreviations}

H7N9: avian influenza A

SARS: severe acute respiratory syndrome

TF-IDF: term frequency-inverse document frequency

Edited by G Eysenbach; submitted 12.07.20; peer-reviewed by Y Xiang, J Lei, C Xu; comments to author 30.07.20; revised version
received 18.08.20; accepted 22.01.21; published 15.02.21
Please cite as:
Chen B, Chen X, Pan J, Liu K, Xie B, Wang W, Peng Y, Wang F, Li N, Jiang J
Dissemination and Refutation of Rumors During the COVID-19 Outbreak in China: Infodemiology Study
J Med Internet Res 2021;23(2):e22427
URL: $\underline{\text { http://www.jmir.org/2021/2/e22427/ }}$
doi: $\underline{10.2196 / 22427}$
PMID: $\underline{3493124}$

CBin Chen, Xinyi Chen, Jin Pan, Kui Liu, Bo Xie, Wei Wang, Ying Peng, Fei Wang, Na Li, Jianmin Jiang. Originally published in the Journal of Medical Internet Research (http://www.jmir.org), 15.02.2021. This is an open-access article distributed under the terms of the Creative Commons Attribution License (https://creativecommons.org/licenses/by/4.0/), which permits unrestricted use, distribution, and reproduction in any medium, provided the original work, first published in the Journal of Medical Internet Research, is properly cited. The complete bibliographic information, a link to the original publication on http://www.jmir.org/, as well as this copyright and license information must be included. 